\title{
PERCEPÇÃO DE QUALIDADE EM SERVIÇOS DE ENSINO SUPERIOR
}

\section{PERCEPTION OF QUALITY IN HIGHER EDUCATION SERVICES}

\author{
LUCIANO DE OLIVEIRA SIQUEIRA \\ Universidade de Passo Fundo (UPF) \\ Doutor em Ciências Biológicas - Universidade Federal do Rio Grande do Sul (UFRGS) \\ Orcid: http://orcid.org/0000-0002-0415-2226 \\ E-mail: luciano@upf.br \\ Instituto de Ciências Biológicas / Curso de farmácia \\ BR 285 km 171, CEP: 99052-900 - Passo Fundo (RS)

\section{LUIZ FERNANDO FRITZ FILHO} \\ Docente do PPG em Administração - Universidade de Passo Fundo (UPF) \\ Doutor em Desenvolvimento Rural - Universidade Federal do Rio Grande do Sul (UFRGS) \\ Orcid: https://orcid.org/0000-0002-0149-9291 \\ E-mail: fritz@upf.br
}

Submissão: 08/07/2020. Revisão: 24/03/2021. Aceite: 29/03/2021. Publicação: 01/02/2022. DOI: http://dx.doi.org/10.22277/rgo.v15i1.5634

\section{RESUMO}

Objetivo: A expansão do ensino superior no Brasil observado nas últimas duas décadas acirrou a competição entre as Instituições de Ensino Superior (IES) e se apresenta como um grande desafio para gestores destas instituições. O objetivo deste estudo foi desenvolver uma ferramenta de marketing para analisar a satisfação de serviços prestados em IES mediante unificação das ferramentas SERVQUAL, SERVPREF, ECSI e questionário do ENADE.

Método / abordagem: Aplicou-se um questionário constituído de 51 constructos divididos em 7 dimensões (aspectos acadêmicos, empatia, aspectos curriculares, confiança, imagem, lealdade, satisfação e infraestrutura) a 373 alunos de uma unidade acadêmica constituída de 7 cursos.

Principais resultados: $A$ análise dos resultados mostra uma forte correlação entre o conceito do ENADE e aspectos acadêmicos; indiretamente os aspectos curriculares, satisfação e lealdade. Por outro lado, imagem, empatia, confiança e infraestrutura, mostram uma forte correlação intergrupo.

Contribuições metodológicas / sociais / gerenciais: os aspectos curriculares, seguido de aspectos acadêmicos são as dimensões que mais impactam na satisfação do aluno de ensino superior.

Originalidade / relevância: O presente estudo inova em integrar diferentes ferramentas de marketing de forma aplicada ao ensino de nível superior.

Palavras-chave: SERVQUAL, SERVPREF, ENADE, Índice de Satisfação do Cliente.

Este é um artigo publicado em acesso aberto (Open Access) sob a licença Creative Commons Attribution, que permite uso, distribuição e reprodução em qualquer meio, sem restrições desde que o trabalho original seja corretamente citado. 


\begin{abstract}
Purpose: The expansion of higher education in Brazil observed in the last two decades has stimulated the competition between Higher Education Institutions (HEIs) and presents itself as a major challenge for managers of these institutions. The aim this study was to develop a marketing tool to analyze the satisfaction of services provided in HEI through the unification of the SERVQUAL, SERVPREF, ECSI and ENADE questionnaires.

Method / approach: A questionnaire consisted of 51 constructs divided into 7 dimensions (academic aspects, empathy, curricular aspects, trust, image, loyalty, satisfaction, and infrastructure) was applied to 373 students from an academic unit consisting of 7 courses.

Main findings: The analysis of the results shows a strong correlation between the concept of ENADE and academic aspects; indirectly the curricular aspects, satisfaction, and loyalty. On the other hand, image, empathy, confidence and infrastructure show a strong inter-group correlation.
\end{abstract}

Methodological / social / managerial contributions: the curricular aspects, followed by academic aspects are the dimensions that most impact on the satisfaction of the student of higher education.

Originality / relevance: This study innovates in integrating different marketing tools in an applied way to higher education.

Keywords: SERVQUAL, SERVPREF, ENADE, Customer Satisfaction Index.

\title{
1 INTRODUÇÃO
}

O aumento de renda promovida pelo plano Real (1994) e a facilidade em acesso ao ensino superior promoveu uma expansão do número de vagas de ingresso. A expansão de cursos de ensino superior, em especial na rede privada, pode não ter sido acompanhada de ganho de qualidade de ensino. A aprovação das Diretrizes e Bases da Educação Nacional (BRASIL, 1996), partir de 1995 a lei 9.131 (Brasil, 1995) permitiu a implantação de um processo avaliativo das Instituições de Ensino Superior que vem sendo sistematicamente aprimorado, mas que ainda necessita de refinamento para a excelência de ensino no país.

Há muito se estuda a percepção de qualidade em serviços utilizando ferramentas de marketing como SERVQUAL, SERVPREF e ECSI (European Customer Satisfaction Index) de forma isolada. A análise destas ferramentas mostra que muitas se sobrepõem, mas que por outro lado mostram-se complementares, tornando incompleta a avaliação dos resultados.

Baseado no exposto o objetivo do presente estudo foi desenvolver uma ferramenta de percepção de qualidade de ensino superior mediante unificação destas ferramentas de marketing, juntamente com o questionário do ENADE e determinar a percepção de qualidade de ensino comparando com o conceito de desempenho do curso no Ministério da Educação obtida no ciclo avaliativo do SINAES (2016). Esta unificação permitiu eliminar as sobreposições e integrar potencialidades, proporcionando o desenvolvimento de uma nova ferramenta de percepção de qualidade aplicado ao ensino superior.

A ferramenta unificada e aplicada foi constituída de um questionário de 51 constructos divididos em sete dimensões, sendo estas: aspectos acadêmicos, empatia, aspectos curriculares, confiança, imagem, lealdade, satisfação e infraestrutura. 
Aspectos acadêmicos (docente qualificado, oportunidades de pesquisa, extensão, palestras, cursos, intercâmbios, metodologia de ensino, monitores, processos avaliativos e uso de tecnologias inovadoras) impactam diretamente no conceito do ENADE. De forma indireta, mas proximamente relacionadas ao ENADE, estão os aspectos acadêmicos e curriculares, (currículo voltado às demandas do mercado, aulas com aplicação pratica, estágios com vivências reais, aprimoramento de competências e habilidade), é o que mais impacta na satisfação e lealdade dos alunos.

A aplicação desta ferramenta de percepção de qualidade de ensino permitirá às IES identificar fragilidades, potencializar forças e desenvolver políticas de aprimoramento de qualidade em busca da excelência do ensino.

\section{REVISÃO DA LITERATURA}

O ensino superior no Brasil apresentou uma grande expansão nas últimas duas décadas, gerando na abertura de novas instituições de ensino superior, novos cursos e consequentemente ampliação de novas vagas de ingresso. A multiplicação de novas IES pode ser explicado por um conjunto de fatores como flexibilização dos critérios para abertura de novos cursos promovidos pelo Ministério da educação, políticas de governo, estabilidade econômica, aumento do número de matrículas no ensino médio, exigência do mercado por colaboradores mais capacitados e qualificados estão entre as principais causas (Mello et al., 2001; Croning Jr \& Taylor, 1994; Lourenço \& Knop 2011).

Com vistas a expandir e regulamentar o acesso ao ensino superior, as Diretrizes e Bases da Educação Nacional foram aprovadas na Lei no 9394/96 (BRASIL, 1996), permitiu a flexibilização do desenvolvimento de cursos superiores e estabeleceu processos regulares de avaliação para credenciamento e recredenciamento de IES no país.

Figura 1

Número de Instituições de Ensino Superior no Brasil de acordo com sua organização administrativa

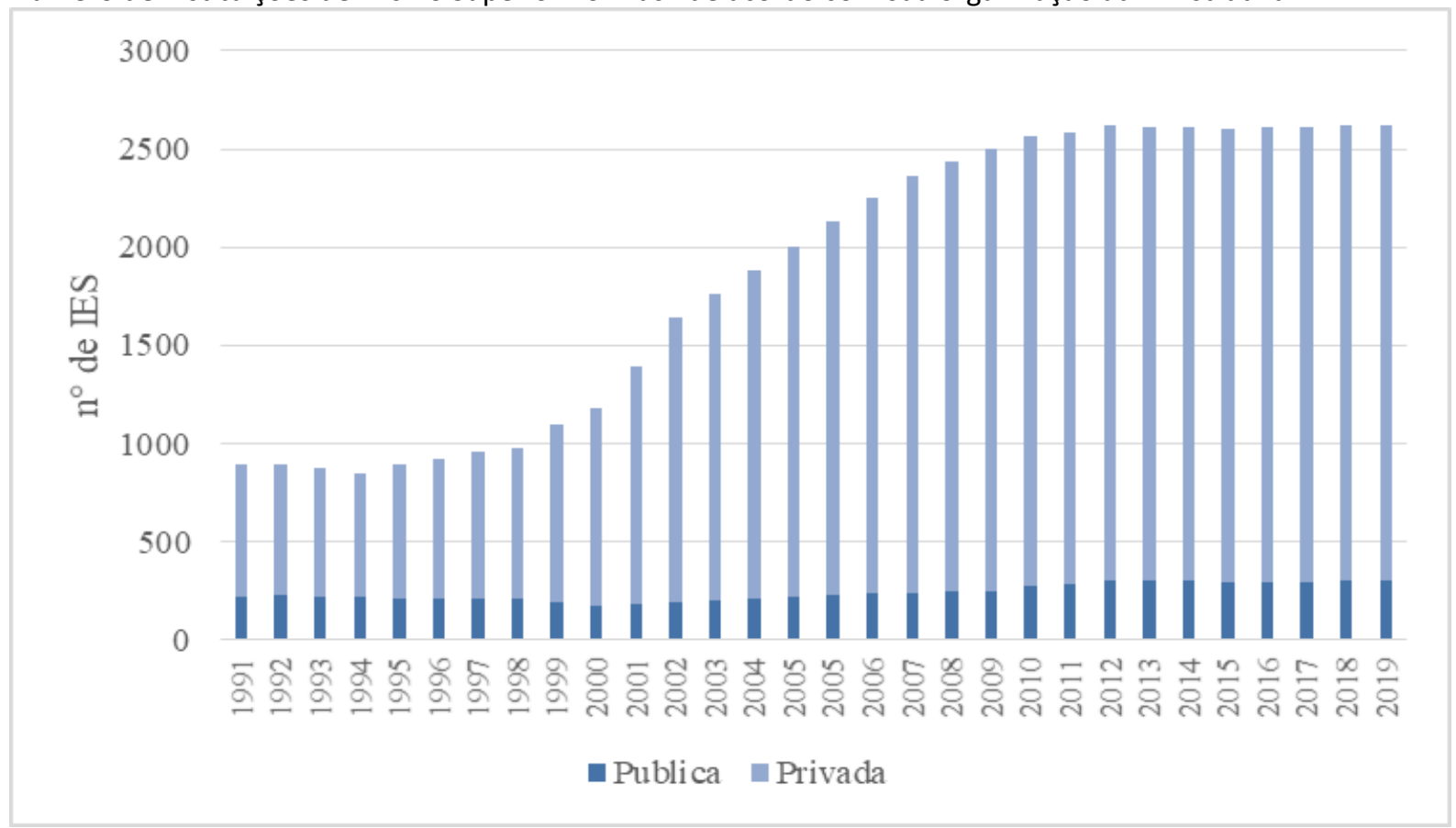

Fonte: INEP (2018). 
A Figura 1 mostra que a implantação do Plano Real iniciado em 27 de fevereiro de 1994, combinada com fatores de mercado e a aprovação da lei 9394/96 (Brasil, 1996) promoveu um aumento significativo no número de novas IES, principalmente na rede privada. Dados do INEP de 2018 apontam que entre 1991 e 2018 houve um crescimento de novas IES na rede pública federal na ordem de $88 \%$, na rede pública estadual na ordem de $58 \%$, na rede privada de $202 \%$ combinada a uma redução de $12 \%$ na rede pública municipal, aproximadamente.

No entanto, este crescimento ocorreu de maneira desordenada. Em razão de sua extensão continental, a distribuição e oferta de novos cursos no Brasil é realizada de forma irregular. Dados do e-MEC (2018) apontam que oferta de cursos superiores na região sudeste e sul é significativamente maior que em outras regiões do Brasil, em razão do produto interno bruto (PIB) e número de habitantes, em especial nas regiões metropolitanas.

Com intuito de conhecer a realidade regional dos cursos da área da saúde do Rio Grande do Sul, dados do IBGE apontam que o estado concentra aproximadamente 5,9\% da população brasileira que produz cerca de $11,7 \%$ do produto interno bruto (PIB) brasileiro. 0 PIB per capita torna um estado atraente para a abertura e oferta de cursos de nível superior na área da saúde, principalmente na rede privada.

Dados do último ciclo avaliativo do ENADE de 2020 corroboram esses achados. A tabela 1 aponta que oferta de cursos da área da saúde por habitante no Rio Grande do Sul é maior que a média nacional. Cursos como fonoaudiologia, estética e cosmética chegam a ser $100 \%$ e $67 \%$ superior que a média nacional, respectivamente.

Tabela 1

Número de cursos da área da saúde oferecidos no Brasil, no Rio Grande do Sul e o percentual de cursos alocados no estado do Rio Grande do Sul

\begin{tabular}{|c|c|c|c|c|c|c|}
\hline & $\begin{array}{c}\mathrm{N}^{\circ} \text { de IES } \\
\text { Brasil }\end{array}$ & $\begin{array}{l}\mathrm{N}^{\circ} \text { de } \\
\text { IES no } \\
\text { RS }\end{array}$ & $\begin{array}{l}\% \text { das } \\
\text { IES no } \\
\text { RS }\end{array}$ & $\begin{array}{l}\mathrm{N}^{\circ} \text { de IES no } \\
\text { Brasil/milhão } \\
\text { de habitantes }\end{array}$ & $\begin{array}{l}\mathrm{N}^{\circ} \text { de IES } \\
\text { no RS/ } \\
\text { milhão de } \\
\text { habitantes }\end{array}$ & $\begin{array}{c}\text { Comparação } \\
\text { de IES/milhão } \\
\text { de habitantes } \\
\text { no RS }\end{array}$ \\
\hline Enfermagem & 800 & 47 & $5,9 \%$ & 3,8 & 4,2 & $\uparrow 11 \%$ \\
\hline Estética e cosmética & 197 & 17 & $8,6 \%$ & 0,9 & 1,5 & $\uparrow 67 \%$ \\
\hline Farmácia & 431 & 24 & $5,6 \%$ & 2,1 & 2,1 & $0 \%$ \\
\hline Fisioterapia & 525 & 34 & $6,5 \%$ & 2,5 & 3,0 & $\uparrow 20 \%$ \\
\hline Fonoaudiologia & 73 & 7 & $9,6 \%$ & 0,3 & 0,6 & $\uparrow 100 \%$ \\
\hline Medicina & 232 & 13 & $5,6 \%$ & 1,1 & 1,2 & $\uparrow 10 \%$ \\
\hline Nutrição & 423 & 27 & $6,4 \%$ & 2,0 & 2,4 & $\uparrow 20 \%$ \\
\hline Odontologia & 238 & 16 & $6,7 \%$ & 1,1 & 1,4 & $\uparrow 28 \%$ \\
\hline
\end{tabular}

Fonte: ENADE 2020.

Mesmo antes da aprovação das Diretrizes e Bases da Educação Nacional (Brasil, 1996), a partir de 1995 a lei 9.131 (Brasil, 1995) permitiu a implantação de um processo avaliativo nos egressos dos cursos de graduação, denominado Exame Nacional de Cursos, conhecido popularmente como "Provão". O exame de larga escala avaliava os cursos em seus aspectos qualitativos mais amplos (Cortelazzo et al., 2021).

O aumento da oferta de vagas e a exploração comercial de cursos de nível superior fez com que se estabelecesse critérios mínimos para garantia de formação de profissionais competentes para o mercado de trabalho mediante a criação de meios mais criteriosos de 
avaliação da qualidade em ensino superior. Com a aprovação da Lei 10.861 em 2004, instituiuse o Sistema Nacional de Avaliação da Educação Superior (SINAES), com uma proposta de avaliação globalizada, caracterizada com avaliações externas, internas e desempenho dos egressos através do Exame Nacional de Desempenho dos Estudantes (ENADE) (Brasil, 2004).

Desde 1995 o sistema de avaliação de qualidade do ensino superior vem evoluindo, que atualmente com SINAES tornou-se um indicador de qualidade da Educação Superior do País (Cortelazzo et al., 2021).

A grande recessão brasileira iniciada em 2014 (Oreiro, 2017) e a busca de recursos humanos cada vez mais capacitados, tem avançado muito na agenda das IES se tornarem cada vez mais competitivas por meio da valorização de atributos relativos a serviços, qualidade de ensino e de infraestrutura (Milan et al., 2015), além da garantia de sua sustentabilidade econômico-financeira.

Nesse contexto, apesar dos avanços da avaliação superior implementadas de forma periódica e sistemática pelo Ministério da Educação, o processo de avaliação dos cursos carece de avaliações de caráter subjetivo como a satisfação e lealdade dos clientes com sua respectiva IES. A implementação de instrumentos de avaliação interna torna-se indispensável para qualquer IES comprometida com a melhoria de processos e satisfação do aluno (Gouvea et al., 2016).

A falta de qualidade ou a qualidade percebida como insatisfatória pela IES pode gerar desistência ou desmotivação em relação aos cursos de graduação (Gouvea et al., 2016, Simic \& Carapic, 2008). A qualidade de ensino percebida pelo aluno depende da interação entre os estudantes e a equipe da instituição (docentes, gestores e pessoal de apoio). A escolha da IES depende da imagem institucional, infraestrutura, estrutura de apoio ao aluno, aspectos acadêmicos, localização, acesso e qualidade de entrega dos conteúdos (Gouvea et al., 2016, Jager \& Gbamosi, 2009).

Como já exposto, o aumento do número de IES com novas vagas, combinada com a crise econômica brasileira iniciada em 2014, além de problemas no repasse do Financiamento Estudantil (FIES), acirrou a competição entre as instituições de ensino superior (IES), em especial as IES privadas ou não-públicas. Este conjunto de eventos desafia dos gestores das IES em busca de alternativas de sustentabilidade econômico-financeira. Neste contexto, os gestores das IES estão cada vez mais preocupados em tornarem suas instituições competitivas na percepção de seus alunos por meio de atributos como qualidade de ensino, serviços e de infraestrutura (Mello et al., 2001; Cavalheiro et al., 2014).

A gestão do ensino superior é pautada de grande complexidade e controvérsias. Uma delas diz respeito a adaptação das IES as realidades e exigências do mercado e o foco social que a define como sendo sem fins lucrativos e de rentabilidade (Carvalho et al., 2008), como é o caso das universidades públicas não-estatais. Aspectos morais e éticos à parte, com foco a sustentabilidade econômico-financeira (uma vez que sem sustentabilidade a existência da IES é inviabilizada), as IES devem se adaptar a demanda com um sensível controle gerencial para superar a concorrência (Tureta et al., 2007).

Neste contexto, a gestão de qualidade de serviços e de ensino em IES é um assunto emergente e de extrema relevância, pois desafia os gestores no desenvolvimento de estratégias de posicionamento do mercado sem esquecer a premissa básica para a existência de uma IES: o ensino de qualidade.

Para atender essas necessidades, o monitoramento de resultados por medidas estatais (Sistema Nacional de Avaliação do Ensino Superior - SINAES), carece de informações para 
tomada de decisões estratégicas de uma IES. Nesse sentido, a avaliação interna empreendida pelas próprias IES adquire importância fundamental (Carvalho et al., 2008; Tureta et al., 2007).

A necessidade do desenvolvimento de uma comissão própria de autoavaliação atuante torna-se imperiosa, uma vez que os resultados de suas análises podem fornecer importantes informações de gestão administrativa sem perder o foco no aprimoramento da qualidade do ensino e de serviços. As comissões têm autonomia para o desenvolvimento de processos de auto avaliação com vistas a respeitar as particularidades sócio regionais das IES brasileiras. Por esta razão os processos auto avaliativos e de percepção de qualidade de ensino e serviços das universidades não são padronizados.

Nesta linha, para auxiliar a gestão das IES algumas ferramentas de marketing foram desenvolvidas como modelos de pesquisa de satisfação e de percepção de qualidade de serviços. Estas ferramentas de marketing foram adaptadas para serem utilizadas para análise de qualidade de ensino em IES, dentre elas a SERVQUAL, SERVPREF e ECSI (European Customer Satisfaction Index - modelo europeu), cada uma com suas particularidades e limitações. Dentre outros itens de avaliação, o Ministério da Educação também desenvolveu um formulário de avaliação que está contido em um dos critérios proposto pelos SINAES: o questionário do ENADE.

Os diferentes serviços ofertados pelo mercado utilizam a avaliação da percepção de qualidade pelo cliente como parte da necessidade de um modelo de mensuração de fenômenos relacionados com o comportamento do cliente, centrados na qualidade dos serviços prestados. Nesse sentido, vários modelos foram desenvolvidos como o SERVQUAL (Parasuraman et al., 1985) e SERVPREF (Croning Jr \& Taylor, 1994). Tais modelos possibilitaram o desenvolvimento de novos instrumentos de mensuração uma vez que o foco do estudo vai além da qualidade percebida, que é a satisfação do cliente (Cavalheiro et al., 2014).

A seguir são apresentadas as principais ferramentas de marketing utilizadas em ensino superior e devidamente validadas pela comunidade científica internacional. A escala SERVQUAL é um modelo de análise de qualidade baseado no princípio da desconfirmação de expectativas, onde os consumidores estarão satisfeitos ou não, se o desempenho do prestador estiver acima ou abaixo de suas expectativas (Parasuraman et al., 1985; Parasuraman et al., 1991; Parasuraman et al., 1998). A escala SERVQUAL é utilizada para mensurar a percepção de qualidade em serviços buscando comparar expectativas e percepções de desempenho. As dimensões avaliadas são: tangibilidade, confiabilidade, presteza, segurança e empatia.

Alegando limitações da ferramenta SERVQUAL, Cronin Jr \& Taylor (1994) propuseram um modelo de avaliação de qualidade em serviços com escalas alternativas (SERVPREF). Este modelo utiliza uma abordagem diferente não considerando a expectativa dos clientes, avaliando apenas suas percepções de qualidade.

O desenvolvimento do ECSI partiu do modelo americano (American Society for Quality Control - ASQC), que considerava aspectos como reclamação e lealdade. O ECSI se destaca dos demais por considerar a imagem a primeira dimensão a ser trabalhada, pois espera que o impacto sobre a imagem traga um efeito direto e positivo na satisfação dos clientes. A segunda dimensão é expectativa em relação ao serviço ofertado, baseadas em experiências positivas e negativas por outros estudantes, salientando as qualidades e defeitos. A terceira dimensão é a qualidade, baseado na avaliação de excelência e superioridade do produto/serviço com relação ao valor percebido. Outra dimensão analisada é a lealdade, que trata da procura ou manutenção do mesmo produto/serviço pelo consumidor, bem como a capacidade de recomendar novos potenciais clientes (Mello et al., 2001). 
O questionário do ENADE é um instrumento de avaliação que tem como fonte as informações do corpo discente. Sendo seu foco o aprendizado, a ferramenta é limitada por não contemplar integralmente as condições de ensino e as competências docentes. Além disso, a medida por amostragem e análise agregada de dados mostram informações insuficientes sobre as atividades de cada IES em particular (Mello et al., 2001; Eberle et al., 2010).

Diante disso, o processo de autoavaliação interna empreendida pelas IES, adquire um papel fundamental na gestão de qualidade de ensino, com vistas a complementar as informações fornecidas pelo Ministério da Educação. A proposição do presente estudo foi desenvolver uma ferramenta de percepção de qualidade de ensino superior mediante unificação de outras ferramentas de marketing em ensino superior já validadas (SERVQUAL, SERVPREF, ECSI e questionário do ENADE); comparar relações entre as dimensões analisadas; determinar a percepção de qualidade de ensino com o conceito de desempenho do curso no Ministério da educação obtida no ciclo avaliativo do SINAES (2016).

\section{ASPECTOS METODOLÓGICOS}

\subsection{Desenho experimental}

Trata-se de um estudo observacional, exploratório, descritivo de corte transversal mediante aplicação de um questionário estruturado com variáveis quantitativas. A pesquisa foi implementada em duas fases: uma qualitativo-exploratória em grupo focal e outra quantitativo-descritiva numa unidade acadêmica de ensino superior constituída de sete cursos de graduação (Ciências Biológicas licenciatura e bacharelado, Enfermagem, Estética e cosmética, Farmácia, Fonoaudiologia, Nutrição), cujos nomes foram aleatoriamente substituídos por letras do alfabeto grego de ALFA a ETA.

\subsection{Casuística}

A amostra utilizada foi não probabilística por conveniência. Com um índice de confiança de 95\% e uma margem de erro de 4,0\%. Dos 1149 alunos regularmente matriculados na unidade, 373 alunos de 7 cursos foram incluídos no estudo, totalizando um percentual de adesão de $32,4 \%$ de toda a unidade

\subsection{Metodologia}

O questionário para pesquisa quantitativa foi baseado no instrumento SERVQUAL, validado por Milan et al. (2015); SERVPREF (Cronin Jr \& Taylor, 1994); ECSI (European Customer Satisfaction Index) validado por Cavalheiro et al. (2014); e questionário do estudante aplicado no ENADE 2016 (INEP, 2017).

Verificou-se que os alguns constructos dos modelos propostos eram muito semelhantes, somente alocados em diferentes tipos de dimensões. Para construção de um modelo único, os constructos semelhantes das quatro ferramentas (SERVQUAL, SERVPREF, ECSI, ENADE) foram reunidos. Os atributos diferentes foram adicionados com intuito de que nenhum constructo avaliado nos modelos já propostos ficasse sem análise. $O$ modelo proposto e aplicado no presente estudo ficou constituído de um formulário de 51 constructos divididos em sete dimensões, sendo estas: aspectos acadêmicos, empatia, aspectos curriculares, confiança, imagem, lealdade, satisfação e infraestrutura.

As dimensões foram dispostas com os constructos do Tabela 2. 
Percepção de qualidade em serviços de ensino superior

Tabela 2

Constructos e suas respectivas dimensões de avaliação de percepção de qualidade aplicadas ao ensino superior, construídas a partir das ferramentas SERVQUAL, SERVPREF. ECSI e questionário do ENADE (2016)

\begin{tabular}{|c|c|}
\hline Dimensões & Constructos \\
\hline 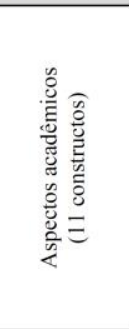 & $\begin{array}{l}\text { 1. Os professores têm conhecimento/capacitação para responder suas questões relativas ao conteúdo de suas disciplinas e do curso? } \\
\text { 2. Os professores apresentam boa didática e são capazes de cativar a atenção do aluno? } \\
\text { 3. Há estimulo e oportunidade de desenvolvimento de pesquisa no seu curso? } \\
\text { 4. Há estimulo e oportunidade de participação em eventos cientificos em seu curso } \\
\text { 5. Há estímulo e oportunidade de desenvolvimento de extensão (projetos de extensão, cursos, palestras, eventos) no seu curso? } \\
\text { 6. Foram oferecidas oportunidades para os estudantes realizarem intercâmbios e/ou estágios dentro e fora do país? } \\
\text { 7. O curso e os professores propiciaram experiências de aprendizagem inovadoras com uso de tecnologias da informação e comunicação } \\
\text { (ambiente virtual de aprendizagem) como estratégia de ensino? } \\
\text { 8. As metodologias de ensino utilizadas no curso desafiaram você a aprofundar conhecimentos e desenvolver competências reflexivas e críticas } \\
\text { 9. O acesso, a qualidade e o acervo dos livros da biblioteca, base de dados, bibliotecas virtuais são adequados? } \\
\text { 10. As avaliações da aprendizagem realizadas durante o curso foram compativeis com os conteúdos ou temas trabalhados pelos professores? } \\
\text { 11. O curso disponibilizou monitores ou tutores para auxiliar os estudantes }\end{array}$ \\
\hline 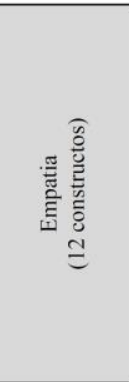 & $\begin{array}{l}\text { 12. A administração (reitoria, direção e coordenação de curso) valoriza as opiniões dos alunos e/ou oportuniza participar de decisões como } \\
\text { representantes em órgãos colegiados? } \\
\text { 13. Os professores compreendem as necessidades especificas dos alunos? } \\
\text { 14. Os professores estimularam você a estudar, aprender e atualizar-se permanentemente? } \\
\text { 15. O pessoal administrativo (secretaria/setor de atendimento ao estudante) tem boa comunicação e compreendem as necessidades especificas dos } \\
\text { alunos } \\
\text { 16. A equipe de secretaria apresenta conhecimento, boa comunicação e disponibilidade na resolução de demandas dos alunos? } \\
\text { 17. Os auxiliares de laboratório apresentam conhecimento e disponibilidade para atender os alunos? } \\
\text { 18. Os auxiliares de limpeza apresentam eficiência e disponibilidade em atender as demandas do curso? } \\
\text { 19. Coordenação do curso: apresenta capacidade de orientação e disponibilidade para resolução de demandas dos alunos? } \\
\text { 20. O aluno tem liberdade de pensamento e expressão e é estimulado a pensar criticamente sobre soluções para problemas da sociedade } \\
\text { 21. Os alunos são estimulados a participar de avaliações periódicas do curso (disciplinas, atuação dos professores, infra-estrutura, auto avaliação). } \\
\text { 22. A instituição tem procedimentos simples, padronizados e individualizadas para oferecer seus serviços? } \\
\text { 23. O curso estimulou a superação de dificuldades mediante articulação da teoria com a prática incentivando dedicação e organização dos estudos? }\end{array}$ \\
\hline 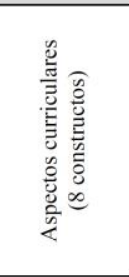 & $\begin{array}{l}\text { 24. O currículo do seu curso está voltado para as demandas do mercado e contribuiram para sua formação integral, como cidadão e profíssional? } \\
\text { 25. Os conteúdos abordados nas disciplinas do curso favoreceram sua atuaça em estágios ou em atividades de iniciação profissional? } \\
\text { 26. O curso proporcionou desenvolvimento da comunicação escrita e oral? } \\
\text { 27. O curso proporcionou formação de uma consciência critica, ética e capacidade de trabalhar em equipe? } \\
\text { 28. O curso proporcionou acesso a conhecimentos atualizados e com atividades práticas suficientes para relacionar os conteúdos do curso com a } \\
\text { prática, contribuindo para sua formação profissional. } \\
\text { 29. Os estágios supervisionados proporcionaram experiências diversificadas para a sua formação? } \\
\text { 30. As atividades realizadas durante seu trabalho de conclusão de curso contribuíram para qualificar sua formação profissional? } \\
\text { 31. As atividades acadêmicas desenvolvidas dentro e fora da sala de aula possibilitaram reflexão, convivência e respeito à diversidade com } \\
\text { promoção da cultura, lazer e de interação social? }\end{array}$ \\
\hline 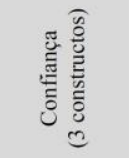 & $\begin{array}{l}\text { 32. Quando o curso/coordenação promete fazer algo em determinado momento ela realmente faz? } \\
\text { 33. A coordenação e secretaria do curso executam rápida e corretamente suas solicitações? } \\
\text { 34. Os professores cumprem os prazos propostos pelos regimentos da universidade? }\end{array}$ \\
\hline 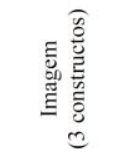 & $\begin{array}{l}\text { 35. Como você percebe as práticas de negócios de universidade (negociação, cobranças, contratos, e etc.)? } \\
\text { 36. Como você percebe a responsabilidade social da universidade (sustentabilidade, filantropia, bolsas e etc.)? } \\
\text { 37. O seu curso em nossa universidade tem uma imagem respeitável e profissional? }\end{array}$ \\
\hline 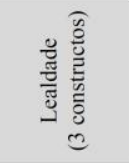 & $\begin{array}{l}\text { 38. Você tem intenção de usar a educação continuada e/ou continuar estudando na universidade em outro curso ou num programa de pós-graduação } \\
\text { (especialização/mestrado)? } \\
\text { 39. Você tem intenção de recomendar a instituição de ensino superior a amigos e familiares? } \\
\text { 40. Se tivesse que escolher uma universidade hoje, você escolheria a UPF novamente? }\end{array}$ \\
\hline 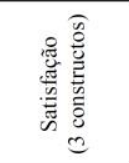 & $\begin{array}{l}\text { 41. Quando comparado com outras instituições de ensino superior, seu curso tem mais qualidade? } \\
\text { 42. Você está satisfeito com a qualidade geral de seu curso? } \\
\text { 43. O curso superou suas expectativas quanto a qualidade }\end{array}$ \\
\hline 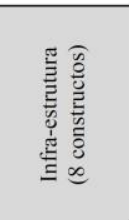 & $\begin{array}{l}\text { 44. Salas de aula: iluminação, conforto térmico e acústico. } \\
\text { 45. Salas de aula: recursos audiovisuais e multimídia. } \\
\text { 46. Laboratórios de aulas práticas: iluminação, conforto térmico, acústico e mobiliário } \\
\text { 47. Laboratórios de aulas práticas: espaço e equipamentos disponiveis. } \\
\text { 48. Limpeza e conservação das dependências do prédio. } \\
\text { 49. Condições de acesso para portadores de necessidades especiais. } \\
\text { 50. Instalações sanitárias (qualidade e limpeza) } \\
\text { 51. Acesso a rede de comunicação (internet e intranet). }\end{array}$ \\
\hline
\end{tabular}


Para versão definitiva do questionário, foi realizado um pré-teste com um grupo focal constituído de oito indivíduos. Procedeu-se a leitura de cada questão do questionário aos participantes e anotou suas respostas. Ao final, os participantes foram questionados acerca de problemas de compreensão das perguntas. As dúvidas foram esclarecidas e corrigidas na versão definitiva contendo sete blocos de perguntas, convertidas do formato digital do Google forms.

Para coleta de dados, o link do formulário eletrônico foi enviado aos participantes por meio da internet. Para impossibilitar que o questionário fosse respondido mais de uma vez, o link de acesso foi codificado. O formulário foi enviado para o e-mail institucional de todos os alunos, ficando online para recebimento de respostas durante 30 dias.

Com intenção de mensurar cada um dos atributos relacionados a qualidade de serviços, foi aplicada uma escala do tipo Likert de cinco pontos, indo do um (conceito mais baixo) a cinco (conceito mais alto).

\subsection{Aspectos éticos}

O trabalho foi desenvolvido segundo declarações e diretrizes sobre pesquisas que envolvem seres humanos: o Código de Nuremberg, Declaração de Helsinque e resolução no 466, de 12 de dezembro de 2012 do Conselho Nacional de Saúde, bem como aprovado e regulamentado pelo Comitê de Ética da instituição executora aprovado sob no de Parecer C.A.A.E. 79886417.2.0000.5342.

\subsection{Análise estatística}

Os resultados foram reunidos e compilados numa planilha de trabalho. Previamente a análise estatística, realizou-se a preparação dos dados, com intenção de detectar erros de digitação e dados omissos (missing) que poderiam comprometer as análises. O método utilizado foi a desconsideração de casos que excediam $10 \%$ da amostra com dados omissos (missing). Desta forma, utilizou-se o método de atribuição, a partir da substituição do valor pela variável nas respostas "não tenho condições de responder" remanescentes no banco de dados.

A partir da planilha de trabalho revisada procedeu-se a análise estatística descritiva e inferencial para determinação das medidas de tendência central e de dispersão dos constructos e das dimensões.

A normalidade da amostra foi testada mediante o teste de Shapiro-Wilk. Apresentando distribuição não-paramétrica, procedeu-se a análise de correlação baseada em processo de comparação de postos, pela determinação do coeficiente de correlação de Spearman com nível mínimo de significância de $p<0,05$. A análise de correlação em comparação de postos, consiste em ordenar os elementos que compõem os dois conjuntos de valores em análise, calculando-se então o coeficiente de correlação de Spearman. Resultados expressos em número absoluto onde:

- $\quad 0.9$ positivo ou negativo indica uma correlação muito forte;

- $\quad 0.7$ a 0.9 positivo ou negativo indica uma correlação forte;

- $\quad 0.5$ a 0.7 positivo ou negativo indica uma correlação moderada;

- $\quad 0.3$ a 0.5 positivo ou negativo indica uma correlação fraca;

- $\quad 0$ a 0.3 positivo ou negativo indica uma correlação desprezível. 


\section{APRESENTAÇÃO DOS RESULTADOS}

Atendendo a resolução 466 de 12 de dezembro de 2012 do CNS, os cursos analisados tiveram sua identificação dada por letras gregas de ALFA a ETA. A análise dos resultados da Tabela 3 mostra a média dos resultados obtidos por curso e dimensão. Os resultados mostram também a estratificação dos conceitos da prova do ENADE obtido por cada curso no último ciclo avaliativo de 2016.

Tabela 3

Conceitos médios das dimensões analisadas de acordo com o curso avaliado

\begin{tabular}{|c|c|c|c|c|c|c|c|c|c|}
\hline 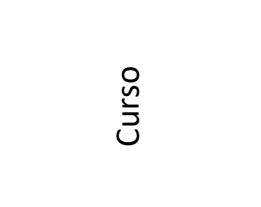 & 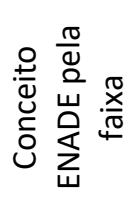 & 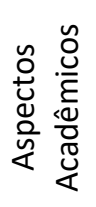 & 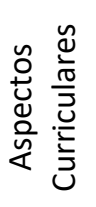 & 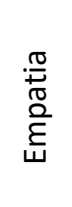 & 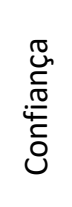 & $\begin{array}{l}\varepsilon \\
\bar{d} \\
00 \\
\tilde{\Xi} \\
\underline{E}\end{array}$ & $\begin{array}{l}\frac{0}{0} \\
\frac{\pi}{0} \\
\frac{\pi}{\pi} \\
\stackrel{9}{4}\end{array}$ & 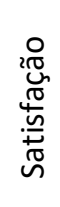 & 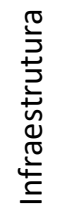 \\
\hline Alfa & 3 & 3,9 & 3,9 & 4,0 & 4,0 & 3,6 & 3,8 & 3,7 & 3,8 \\
\hline Beta & 3 & 3,9 & 4,1 & 4,3 & 4,2 & 4,0 & 4,3 & 4,3 & 4,1 \\
\hline Gama & 3 & 3,8 & 4,1 & 4,0 & 3,9 & 3,8 & 4,3 & 4,1 & 3,9 \\
\hline Delta & 2 & 3,5 & 3,7 & 3,7 & 3,5 & 4,0 & 3,8 & 3,7 & 3,9 \\
\hline Épsilon & 4 & 4,1 & 3,9 & 3,5 & 3,2 & 3,6 & 4,2 & 4,2 & 3,7 \\
\hline Zeta & 2 & 3,4 & 3,5 & 3,2 & 3,0 & 3,1 & 3,5 & 3,1 & 2,7 \\
\hline Eta & 3 & 3,6 & 3,6 & 4,0 & 3,8 & 3,7 & 3,3 & 3,0 & 3,9 \\
\hline Geral da unidade & - & 3,7 & 3,8 & 3,7 & 3,5 & 3,6 & 3,8 & 3,6 & 3,5 \\
\hline
\end{tabular}

Após a análise estatística descritiva dos resultados, determinou-se a média de conceito de cada constructo seguida da média da respectiva dimensão. Os resultados foram distribuídos de acordo com o atributo dado para cada curso conforme demonstrado na Tabela 4.

Tabela 4

Análise de correlação linear por postos entre as dimensões analisadas pela ferramenta proposta no presente estudo conjuntamente com o conceito do ENADE (2016)

\begin{tabular}{|c|c|c|c|c|c|c|c|c|}
\hline & 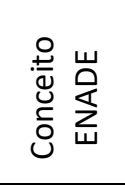 & 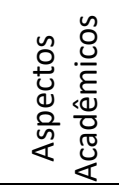 & 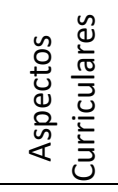 & 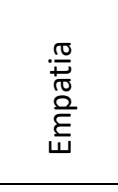 & 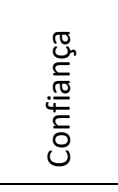 & $\begin{array}{l}\underline{\varepsilon} \\
\mathbb{\Xi} \\
0 \\
\widetilde{\sigma} \\
\underline{\underline{\Xi}}\end{array}$ & $\begin{array}{l}\frac{0}{8} \\
\frac{\pi}{\pi} \\
\frac{\pi}{\pi} \\
\end{array}$ & 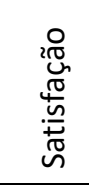 \\
\hline Acadêmico & $0,861 *$ & & & & & & & \\
\hline Curricular & 0,621 & $0,764 *$ & & & & & & \\
\hline Empatia & 0,331 & 0,386 & 0,660 & & & & & \\
\hline Confiança & 0,291 & 0,352 & 0,657 & $0,985^{*}$ & & & & \\
\hline Imagem & 0,045 & 0,290 & 0,580 & $0,745^{*}$ & 0,673 & & & \\
\hline Lealdade & 0,502 & $0,709 *$ & $0,911 *$ & 0,340 & 0,320 & 0,475 & & \\
\hline Satisfação & 0,502 & $0,771 *$ & $0,904 *$ & 0,387 & 0,354 & 0,556 & $0,980^{*}$ & \\
\hline Infraestrutura & 0,341 & 0,510 & 0,651 & $0,850^{*}$ & $0,782 *$ & $0,925^{*}$ & 0,444 & 0,539 \\
\hline
\end{tabular}

Nota: Valores expressos com coeficiente de correlação de Spearman $\left(R^{2}\right)$, sendo * $p<0,05$. 
A análise de correlação linear por postos entre as dimensões mostra uma correlação muito forte e estatisticamente significante que permite dividir as dimensões em 2 grupos que se inter-relacionam:

- Grupo 1: constituído de conceito do ENADE, aspectos acadêmicos, satisfação, lealdade e aspectos curriculares;

- Grupo 2: constituído de imagem, empatia, confiança e infraestrutura.

A análise estatística dos resultados mostra que as inter-relações entre as dimensões do grupo 1 e 2 ocorrem somente intergrupo. As correlações dos resultados entre as variáveis dos grupos 1 e 2 (inter-relação extra grupo) mostraram uma correlação fraca e sem significância estatística, permitindo a estratificação das dimensões nos algoritmos apresentados nas Figuras 2 e 3.

Figura 2

Inter-relações de influência entre as dimensões do grupo 1: conceitos do ENADE, aspectos curriculares, acadêmicos, lealdade e satisfação do aluno

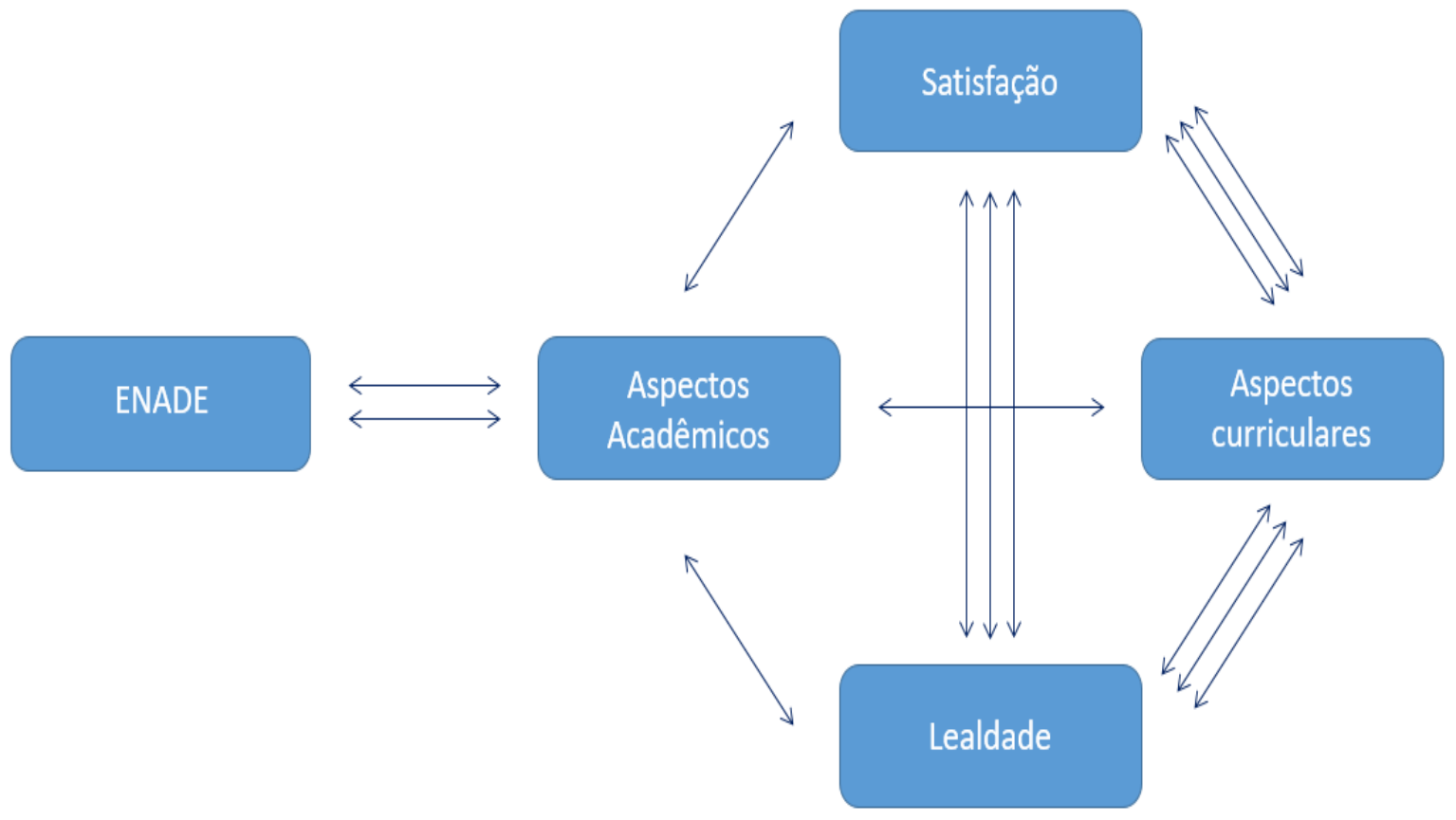

Nota: A direção e número de setas representam o grau de força da relação $\left(R^{2}\right.$ - pela análise de correlação de Spearman)

Todos os resultados descritos na Figura 2 mostraram uma correlação forte e estatisticamente significante $(p<0,05)$. O número de setas representa o grau de força de relação entre as dimensões ( 1 seta $R^{2}=0,700$ a 0,799; 2 setas $R^{2}=0,800$ a 0,899 e 3 setas $R^{2} \geq$ 0,900 pela análise de correlação de Spearman). $O$ valor de $R^{2}$ quanto mais próximo de 1 mais forte é a correlação. A Figura 2 mostra que o conceito do ENADE está diretamente relacionado com os aspectos acadêmicos da IES $\left(R^{2}=0,861\right)$.

Como esperado, a análise dos resultados mostra que um bom desempenho no conceito de ENADE está relacionado a aspectos acadêmicos comum corpo docente qualificado, oportunidades de pesquisa, extensão, palestras, cursos, intercâmbios, metodologia de ensino, monitores, processos avaliativos e uso de tecnologias inovadoras. Aspectos curriculares, de satisfação, lealdade, não apresentam relação direta com o conceito do ENADE, mas impacta de forma indireta. 
As dimensões inter-relacionadas no grupo 1 (Figura 2) apresentaram uma relação fraca e sem significância estatística com as dimensões inter-relacionadas no grupo 2 (Figura 3).

Figura 3

Inter-relações entre as dimensões do grupo 2: percepção do aluno sobre a imagem, confiança, infraestrutura e empatia da instituição.

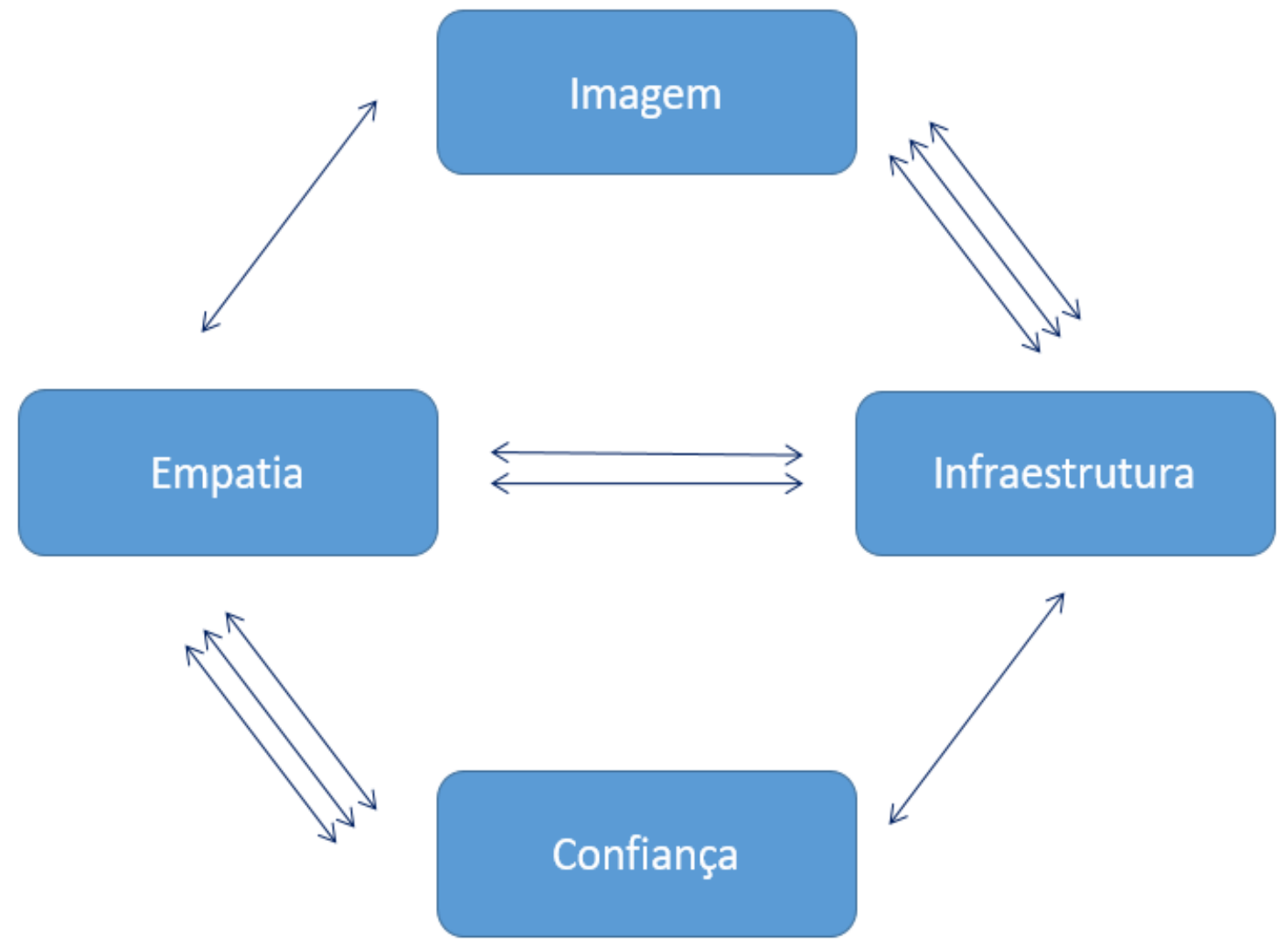

Nota: A direção e número de setas representam o grau de força da relação $\left(R^{2}\right.$ - pela análise de correlação de Spearman)

A análise estatística dos resultados apresentadas na Figura 3 mostra que a empatia (compreensão das necessidades especificas dos alunos, atendimento e disponibilidade de professores e funcionários) impacta de forma muito forte na confiança $\left(R^{2}=0,985\right)$ sentida pelos alunos (quando se cumpre os regimentos, prazos de forma rápida e correta), na infraestrutura $\left(R^{2}=0,850\right)$ e numa imagem institucional respeitável e profissional $\left(R^{2}=0,745\right)$.

\section{DISCUSSÃO DOS RESULTADOS}

Diretamente relacionado aos aspectos acadêmicos e indiretamente ligado ao conceito do ENADE estão os aspectos curriculares que podem e devem contribuir com a qualidade de ensino. A elaboração de um projeto político pedagógico voltado às demandas do mercado, que qualifique o aluno a desenvolver potencialidades de comunicação verbal e não-verbal, capacidade de trabalhar em equipes, aulas com aplicação prática e estágios que proporcionem vivencias reais, são atributos que qualificam os aspectos acadêmicos e consequentemente a qualidade de ensino. 
Os resultados mostram ainda que a satisfação do aluno e sua lealdade (intenção de fazer outros cursos e/ou indicar a universidade para amigos e familiares) estão mais fortemente ligadas aos aspectos curriculares $\left(R^{2}=0,904\right.$ e 0,911 , respectivamente) quando comparado com os aspectos acadêmicos $\left(R^{2}=0,771\right.$ e0, 709, respectivamente). Isso implica dizer que no planejamento estratégico de reestruturação de um curso, os gestores que focarem esforços nos aspectos curriculares estarão automaticamente fortalecendo laços de lealdade e de satisfação do aluno com seu curso de forma mais assertiva quando comparada com os aspectos acadêmicos. Isso não significa dizer que a qualificação docente e do currículo devam ser dissociáveis e/ou priorizadas, pelo contrário, as dimensões se inter-relacionam diretamente e não devem ser segmentadas, necessitando de um olhar reflexivo sobre os objetivos do curso e de seu planejamento estratégico.

Por sua vez, a análise dos resultados obtidos para infraestrutura demonstra haver uma forte correlação estatisticamente significante na imagem institucional $\left(R^{2}=0,925\right)$, e de forma menos evidente na confiança da instituição $\left(R^{2}=0,782\right)$. Isso se deve pelo fato de que a confiança depende mais dos recursos humanos que a infraestrutura em si, mesmo assim, a análise dos resultados mostra uma forte correlação.

Baseado nos resultados obtidos percebe-se que as dimensões do grupo 1 (ENADE, aspectos acadêmicos, curriculares, satisfação e lealdade) estão mais associadas à condução e decisões tomadas pelo corpo docente, onde exerce um papel importante papel na satisfação e lealdade do aluno diante do curso e da IES. Por outro lado, percebe-se que as dimensões do grupo 2 (Empatia, imagem, confiança e infraestrutura) estão fortemente ligadas ás decisões e gestão de recursos humanos (empatia e confiança), infraestrutura e imagem (administrativo). O desenvolvimento e aplicação de uma Matriz SWOT ou FOFA, seguida da análise 5W2H é possível desenvolver um planejamento estratégico robusto e com resultados efetivos.

O presente estudo inova em integrar diferentes ferramentas de marketing de forma aplicada ao ensino de nível superior. Por outro lado, o estudo limita-se pelo fato de que esta integração resultou num questionário extenso que pode gerar resistência nos alunos quando uma vez aplicado em outras instituições de ensino. Sua reestruturação com a redução de constructos e manutenção das dimensões poderão proporcionar uma ferramenta mais enxuta e com maior adesão dos participantes nos processos de auto avaliação.

\section{CONSIDERAÇÕES FINAIS}

A análise dos resultados obtidos permite concluir que os aspectos acadêmicos dos cursos (docente qualificado, oportunidades de pesquisa, extensão, palestras, cursos, intercâmbios, metodologia de ensino, monitores, processos avaliativos e uso de tecnologias inovadoras) impactam diretamente no conceito do ENADE. Indiretamente ao conceito do ENADE, mas intrinsecamente relacionadas, estão os aspectos acadêmicos e curriculares, sendo que um currículo voltado às demandas do mercado, aulas com aplicação pratica, estágios com vivências reais, aprimoramento de competências e habilidade, é o que mais impacta na satisfação e lealdade dos alunos.

Os resultados mostram que os aspectos curriculares, seguido de aspectos acadêmicos são as dimensões que mais impactam na satisfação do aluno de ensino superior. Baseado no exposto, a validação da ferramenta mostrou-se eficiente para análise da percepção de qualidade universitária pois permite a visão holística dos conceitos de marketing de forma integrada e direcionada ao ensino superior, permitindo a correlação com diferentes dimensões. As informações obtidas desta ferramenta fornecem dados valiosos para gestores 
conduzirem estratégias conjuntas (reitoria, gestores, professores), para analisar as dimensões impactadas e condução de seu planejamento estratégico.

\section{REFERÊNCIAS}

Brasil. (1995). Lei no 9.131, de 24 de novembro de 1995. http://www.planalto.gov.br/ccivil_03/LEIS/L9131.htm.

Brasil. (1996). Lei no 9.394, de 20 de dezembro de 1996. http://www.planalto.gov.br/ccivil_03/LEIS/L9394.htm.

Brasil. (2004). Lei no 10861, de 14 de abril de 2004. http://www.planalto.gov.br/ccivil_03/_ato2004-2006/2004/lei/l10.861.htm.

Carvalho, F. A., Aquino, R., \& Tomassini, R. (2008). Expectativas e percepções em sequência de serviços. RAE eletrônica, 7(2). http://dx.doi.org/10.1590/S167656482008000200004 .

Cavalheiro, E. A., Tavares, C. E. M., Ferreira, A. P. A. L., Santos, R. A., \& Stedile, C. S. M. (2014). Modelo europeu de satisfação: um estudo de caso com discentes de uma Instituição de Ensino Superior. GEPROS. Gestão da Produção, Operações e Sistemas, 9(1), 131-141. https://doi.org/10.15675/gepros.v0i1.1122.

Cortelazzo, A. L., Piva Júnior, P., \& Rodrigues, M. R. J. B. (2021). Resultados do exame nacional do desempenho de estudantes - ENADE: quantitativos históricos na área da computação e qualidade dos cursos. Brazilian Journal of Development, 7(1), 865-886.

Croning Jr., J. J, \& Taylor, A. S. (1994). SERVPERF versus SERVQUAL: reconciling performandebased na perceptions-minus-expectations measurement of service quality. Journal of Marketing, 58(1), 125-131. https://doi.org/10.1177/002224299405800110.

Eberle, L., Milan, G. S., \& Lazzari, F. (2010). Identificação das dimensões da qualidade em serviços: um estudo aplicado em uma instituição de ensino superior. RAE-eletrônica, 9(2). https://doi.org/10.1590/S1676-56482010000200003.

e-MEC. Instituições de educação superior e cursos cadastrados. 2016. http://emec.mec.gov.br/.

Gouvea, M. A., Onusic, L. M., \& Mantovani, D. M. N. (2016). Qualidade e lealdade ao curso no ensino superior. Brazilian Journal of Managemanent, 9(1), 26-45. https://doi.org/10.5902/198346597690.

Instituto Brasileiro de Geografia e Estatística. (2021). Conheça cidades e estados do Brasil. https://cidades.ibge.gov.br. 
Instituto Nacional de Estudos e Pesquisa Educacionais Anísio Teixeira. (2016). Questionário do estudante. Brasília, INEP, 2016. Disponível em http://download.inep.gov.br/educacao_superior/enade/questionario_estudante/ques tionario_estudante_enade_2016.pdf.

Instituto Nacional de Estudos e Pesquisa Educacionais Anísio Teixeira. (2016). Sinopse estatística da educação superior 2015. Brasília, INEP. http://inep.gov.br/sinopsesestatisticas-da-educacao-superior.

Jager, J., \& Gbamosi, G. (2009). Specific remedy for specific problem: measuring service quality in south Africa higher education. Higher education, 60(3), p.251-267. https://doi.org/10.1007/s10734-009-9298-6.

Lourenço, C. D. S., \& Knop, M. F. T. (2011). Ensino superior em administração e percepção de qualidade de serviços: uma aplicação da escala SERVQUAL. Revista Brasileira de Gestão de Negócios, 13(39), 219-233. https://doi.org/10.7819/rbgn.v13i39.854.

Malhorta, N. K. (2001). Pesquisa de marketing: uma orientação aplicada. Porto Alegre: Bookman.

Mello, S. C. B., Dutra, H. F. O., \& Oliveira, P. A. S. (2001). Avaliando a qualidade de serviço educacional numa IES: o impacto da qualidade percebida na apreciação do aluno de graduação. Organizações \& Sociedade, 8(21), 125-137. https://doi.org/10.1590/S198492302001000200008.

Milan, G., Eberle, L., Corso, A., \& De Toni, D. (2015). A qualidade em serviços e a satisfação de clientes: comparação entre a percepção de alunos de graduação e pós-graduação de uma IES. Brazilian Journal of Managemanent, 8(3), 415-437. https://doi.org/10.5902/198346599935.

Oliveira, O. J., \& Ferreira, E. C. (2008). Adaptação e aplicação da escala SERVQUAL na educação superior. Gepros: Gestão da Produção, Operações e Sistemas, 3(3), 133-147, 2008. https://doi.org/10.15675/gepros.v3i3.473.

Oreiro, J. L. (2017). A grande recessão brasileira: diagnóstico e uma agenda de política econômica. Estudos Avançados, 31 (39). 10.1590/s0103-40142017.31890009.

Parasuraman, A., Berry, L. L., \& Zeithaml, V. A. (1991). Refinement and reassessment of the SERVQUAL scale. Journal of Retailing, 67(4), 420-450.

Parasuraman, A., Zeithaml, V., \& Berry, L. (1985). Conceptual model of service quality and its implications for future research. Journal of Marketing, 49(4), 41-50.

Parasuraman, A., Zeithaml, V., \& Berry, L. (1998). SERVQUAL: a multiple-item scale for measurement perceptions of service quality. Journal of Retailing, 64(2), 12-40.

Remler, D. K., \& Van Ryzin, G. G. (2011). Research method in practice: strategies for description and causation. Thousand Oaks: Sage Publicatinos. 
Percepção de qualidade em serviços de ensino superior

Simic, M. L., Carapic, H. (2008). Education service quality of a business school: former na current student evaluation. International Review on Public Non Profit Marketing, 5(2), 181-191. https://doi.org/10.1007/s12208-008-0019-0.

Tureta, C., Rosa, A. R., \& Oliveira, V. C. S. (2007). Avaliação crítica de serviços educacionais: o emprego do modelo SERVQUAL. REGE: Revista de Gestão, 14(4), 33-45. 